Article

\title{
Mass Transport Optimization for Redox Flow Battery Design
}

\author{
Nicholas Gurieff ${ }^{1 \oplus}$, Declan Finn Keogh ${ }^{1}$, Mark Baldry ${ }^{2,3}{ }^{\oplus}$, Victoria Timchenko ${ }^{1}$, \\ Donna Green ${ }^{4}{ }^{\mathbb{D}}$, Ilpo Koskinen ${ }^{5}$ and Chris Menictas ${ }^{1, *}$ \\ 1 School of Mechanical and Manufacturing Engineering, UNSW, Sydney, NSW 2052, Australia; \\ n.gurieff@unsw.edu.au (N.G.); d.keogh@unsw.edu.au (D.F.K.); v.timchenko@unsw.edu.au (V.T.) \\ 2 School of Biomedical Engineering, The University of Sydney, Sydney, NSW 2006, Australia; \\ mark.baldry@sydney.edu.au \\ 3 School of Physics, The University of Sydney, Sydney, NSW 2006, Australia \\ 4 Climate Change Research Centre, UNSW, Sydney, NSW 2052, Australia; donna.green@unsw.edu.au \\ 5 Design Next, UNSW, Sydney, NSW 2052, Australia; ilpo.koskinen@unsw.edu.au \\ * Correspondence: c.menictas@unsw.edu.au; Tel.: +61-2-9385-6269
}

Received: 14 February 2020; Accepted: 15 April 2020; Published: 17 April 2020

Featured Application: The wedge-shaped cells with static mixers simulated in this research can be applied to innovative high-performance toroidal vanadium redox flow battery (VRB/VRFB) designs for commercial development in public settings/urban environments.

\begin{abstract}
The world is moving to the next phase of the energy transition with high penetrations of renewable energy. Flexible and scalable redox flow battery (RFB) technology is expected to play an important role in ensuring electricity network security and reliability. Innovations continue to enhance their value by reducing parasitic losses and maximizing available energy over broader operating conditions. Simulations of vanadium redox flow battery (VRB/VRFB) cells were conducted using a validated COMSOL Multiphysics model. Cell designs are developed to reduce losses from pump energy while improving the delivery of active species where required. The combination of wedge-shaped cells with static mixers is found to improve performance by reducing differential pressure and concentration overpotential. Higher electrode compression at the outlet optimises material properties through the cell, while the mixer mitigates concentration gradients across the cell. Simulations show a $12 \%$ lower pressure drop across the cell and a $2 \%$ lower charge voltage for improved energy efficiency. Wedge-shaped cells are shown to offer extended capacity during cycling. The prototype mixers are fabricated using additive manufacturing for further studies. Toroidal battery designs incorporating these innovations at the $\mathrm{kW}$ scale are developed through inter-disciplinary collaboration and rendered using computer aided design (CAD).
\end{abstract}

Keywords: vanadium redox flow battery; power density; limiting current; cell geometry; mass transfer; electrolyte mixing; static mixer; industrial design; multidisciplinary research; energy transitions

\section{Introduction}

The transformation of our energy systems including generation, distribution and storage is rapidly underway around the world. This process requires the ability to intelligently manage electricity supply and demand via digital smart grids. Power networks will need to manage existing requirements, new demands such as electric vehicles, and an increase in variable asynchronous generation. A key enabler of this development will be large-scale energy storage, particularly batteries [1]. Amongst commercially available technologies, redox flow batteries (RFBs) stand out with their inherent technical 
advantages: long lifetimes, recyclable materials, non-flammable electrolytes, and independent power and capacity scaling. Scale is an important consideration for flow batteries as energy capacity costs can be lower than those of Li-ion for large scale applications [2].

The scalability of true redox flow batteries such as the vanadium redox flow battery (VRB/VRFB) is due to the manner that energy $(\mathrm{kWh} / \mathrm{MWh})$ is stored in liquid electrolyte tanks while energy conversion/power delivery (kW/MW) takes place in stacks similar to fuel cells. Unlike in fuel cells, however, and some hybrid technologies, the power conversion process in an RFB is reversible. In the case of VRBs, active vanadium ions supported in a sulfuric acid solution react when passed through conductive porous electrodes in two half-cells separated by an ion-selective membrane. The porous media, in the form of carbon paper or felt, is used to increase active surface area. To construct stacks with higher voltages, cells are linked together by solid bipolar electrodes, mechanically in parallel and electrically in series.

The power generated by a battery stack as the electrolyte flows through the cells under an applied current is the product of the current and the voltage. The voltage of a cell, $V_{\text {cell }}$, is described below in Equation (1) [3]:

$$
V_{\text {cell }}=E^{C}+E^{A}-\eta_{A}-\eta_{C}-i R_{\text {cell }}
$$

where $i$ is the current, $R_{\text {cell }}$ is the ohmic resistance, $E_{C}$ and $E_{A}$ are the reversible cathode and anode potentials, respectively. Activation overpotential, $\eta_{A}$, is the polarisation potential required to overcome the activation energy barrier for both cathode and anode electron transfer reactions. Both charge and discharge require adequate delivery of reactants to maintain elevated power densities, particularly at the extremes of the battery's State of Charge (SOC). Mass-transport limitations within the cell can result in electrode material degradation, hazardous gas evolution and a reduction in overall system performance. Current and flow rate must be regulated appropriately to balance pumping losses with system demands in order to avoid this. This limits the power density of Redox Flow Battery (RFB) systems [3,4] and the parasitic phenomenon is known as concentration polarization. The concentration overpotential, $\eta_{C}$, can become the dominant term in this situation. The limiting current density in this limiting case, $i_{L}$, is then expressed as shown in Equation (2) [4]:

$$
i_{L}=n F k_{m} C_{b}
$$

where $n$ is the number of electrons in the reaction and $C_{b}$ is the bulk reactant concentration in mol m $\mathrm{m}^{-3}$. The local mass transfer coefficient, $k_{m}$, in $\mathrm{m} \mathrm{s}^{-1}$ is a function of convective fluid velocity, $v$, in $\mathrm{m} \mathrm{s}^{-1}$ as shown in Equation (3) [4]:

$$
\mathrm{k}_{\mathrm{m}}=1.6 \times 10^{-4} \cdot v^{0.4}
$$

Considerable attention has been devoted to the development of new cell materials, electrodes and reaction mechanisms [5], while electrolyte flow and the associated mass-transfer effects remains to be satisfactorily addressed [6]. Without turbulence or mechanical interventions, diffusion-limited flow conditions result in reactants being depleted close to boundaries. Cell design aimed at this issue predominately use fuel cell-inspired flow fields, particularly interdigitated and serpentine channels [7], despite pressure drop challenges associated with scaling up to industrially relevant battery stack sizes [8]. Commercial scale cells rely on traditional flow-through configurations as the parasitic pressure drop associated with interdigitated and serpentine flow fields remains too high.

Assessing larger cells is thus key for implementation, although experimental work on cells at that scale is more difficult, especially when the goal is to examine internal phenomena. Simulation with numerical models provides a more accessible means, and have been used since Shah and co-workers published their dynamic two-dimensional models [9-11]. Researchers have since developed more versatile coupled mechanical and electrochemical models. You et al. [12] published a simplified stationary model, which was then adapted to a three-dimensional domain [13]. Other groups have included considerations such as vanadium crossover and water transport between half-cells [14]. 
Novel cell geometries, including trapezoidal [15] and radial designs [16], have been explored with the aid of these models, helping to show the potential of design modifications for flow-through cell performance enhancement. Unfortunately, initial research into these particular designs found them to be susceptible to uneven distribution across the cell and increased pressure drop through the cell. An alternative approach, involving progressive reduction of the cross-sectional area to provide increased electrode compression and higher flow rate towards the outlet, showed it is possible to improve both electrochemical and mechanical performance with innovative design [17]. Subsequent experimental testing on laboratory-scale cells demonstrated improved energy efficiencies with wedge shaped cells, and a toroidal stack concept based on this concept was presented at the International Flow Battery Forum [18].

The effect of felt compression has been well documented $[19,20]$ and other studies have applied the same theory in different ways, such as by modifying the materials instead of the cell geometry [21-23]. Another group has modified the cell architecture with asymmetric compression to address species crossover and associated capacity decay [24]. The problem of concentration gradients across the half-cell cross-section between the solid current collector and the membrane persists with these innovations and others like the circular concept proposed by Zheng at al. [13,25].

The application of static mixers has been proposed to address this problem [26], but not in conjunction with varied compression. Conductive static mixers have previously been used in experiments with slurry electrode VRBs [27] and other electrochemical flow cells [28]. Subsequent research with inert mixers and conventional electrolytes showed enhanced electrochemical performance with a small pressure differential. The power consumed by pumps is a fraction of overall energy so a minor increase in power use can be offset by electrochemical improvements, though design refinement can also mitigate this pressure differential and further improve overall performance. There is no reason why varied electrode compression cannot by applied in the same cell, so in this work we assess the impact of combining the two innovations. Figure 1 provides a visual representation of this concept.

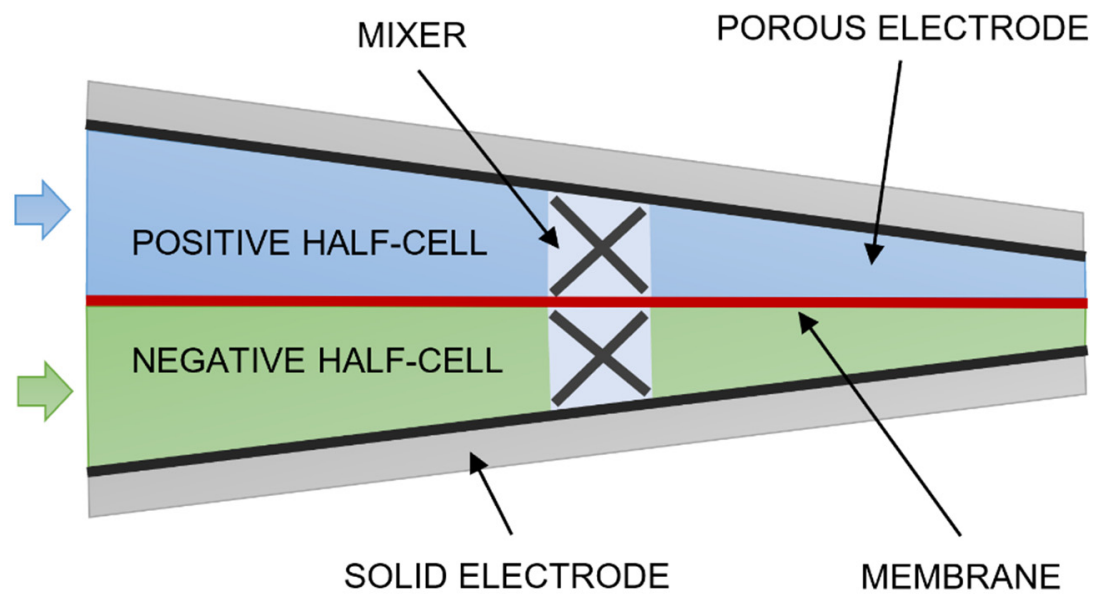

Figure 1. Single cell diagram showing mixers in a wedge-shaped cell with flow from left to right. Note there is a gap in the porous material in the mixer volume.

\section{Materials and Methods}

This research used an approach based on a combination of methods applied in prior published work conducting validated multiphysics simulations of VRB half-cells [16], 2D wedge full-cells [17] and then 3D cells with mixers [26]. A concise overview and key parameters are provided here, with further details of the model available in Appendix A of this paper.

Previous simulations of wedge-shaped cells with increasing compression used 2D models for computational resource efficiency. This model, with variable porous electrode parameters, 
was transferred into a 3D model in order to enable the assessment of geometries with mixers which cannot be defined in 2D. This model was then used to simulate three cases:

- Case 1-conventional rectangular reference geometry uniformly compressed at 15\% (3.4 mm thick), the average of the $0 \%$ to $30 \%$ compression used in the wedge geometries.

- Case 2-wedge-shaped geometry with $0 \%$ compression $(4 \mathrm{~mm})$ at the inlet and $30 \%$ compression at the outlet $(2.8 \mathrm{~mm})$.

- Case 3-wedge-shaped geometry with $0 \%$ to $30 \%$ compression with a blade-style mixer bounded by an $8 \mathrm{~mm}$ fluid domain.

Based on the findings of previous research [26], 2-element mixers (Figure 2a) were placed at the halfway point in each half cell, which was shown to be the most effective out of the simulated variations. The present study used $400 \mathrm{~cm}^{2}$ scale cells (200 mm length sections) rather than $900 \mathrm{~cm}^{2}(300 \mathrm{~mm}$ length) for higher computational resource efficiency whilst remaining commercially relevant. Full-cell models (geometry with mixers, truncated for easy viewing, shown in Figure 2b) were used to assess the effect of the mixer on cell voltage. The active area of exposed membrane remains almost identical; however, $4 \%$ of the porous electrode is removed to accommodate the mixer. Symmetry boundary conditions were used on both sides of the unit-width geometry to minimize the computational domain.

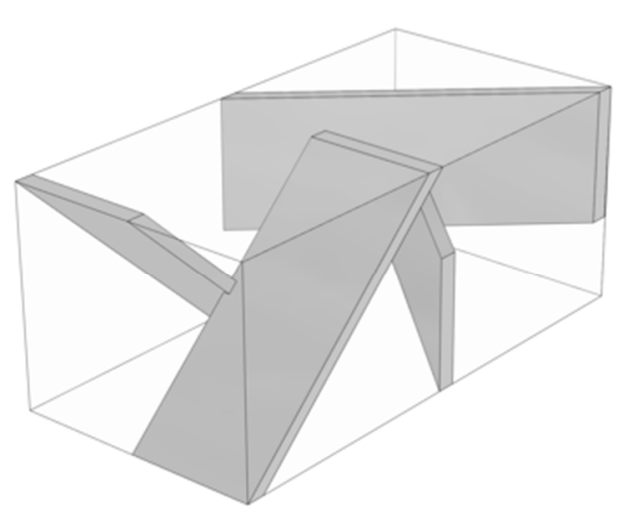

(a)

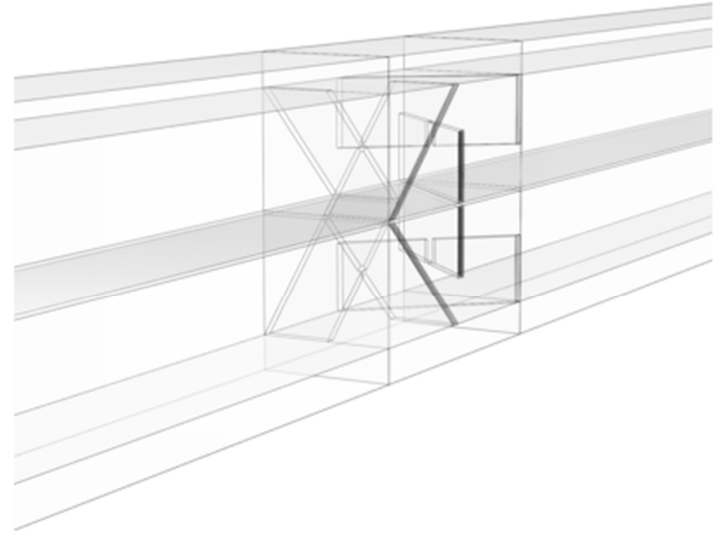

(b)

Figure 2. CAD renders of (a) 2-element blade-type mixer and (b) a section of a unit-width full-cell with mixers in both half-cells. The mixer is $8 \mathrm{~mm}$ long and the cell domain is $200 \mathrm{~mm}$ long and $4 \mathrm{~mm}$ wide.

Meshing strategies resulting from previous refinement studies were used, which were found to achieve convergence for the minimum concentration values that are sensitive to both convective mass transfer and electrochemical processes. Mapped meshes with elements biased towards the outlet and current collector boundaries were used for the rectangular geometry, while the volume surrounding the mixers was discretized with unstructured meshes. Numbers of elements in the order of 200,000 provided acceptable resolution.

Governing equations were applied based on the approach developed by Shah et al. [9] and You et al. [12]. Ion flux is described by the Nernst-Planck equations and the Butler-Volmer law is used to define electrode reaction kinetics, while Darcy's law was applied to give the velocity in the porous electrode. Some elements of the model were taken from Knehr et al. in relation to fluid parameters [14] and the treatment of the boundaries between the membrane and electrodes [29]. Selected SOC values were simulated for model validation as described by You et al. and Zheng et al. [30].

The coupled electrochemical and fluid equations were solved using the finite element method with software package COMSOL Multiphysics using the UNSW Sydney computational cluster, Katana. The general parameters shown in Table 1 were applied to each case. 
Table 1. General operating parameters.

\begin{tabular}{cccc}
\hline Parameter & Symbol & Value & Unit \\
\hline Outlet pressure & $P$ & 0 & $\mathrm{~Pa}$ \\
Temperature & $\mathrm{T}$ & 293.15 & $\mathrm{~K}$ \\
Current density & $i$ & 160 & $\mathrm{~mA} \mathrm{~cm}^{-2}$ \\
ate of Charge & SOC & 90 & - \\
Domain width & $\mathrm{w}$ & $4 \times 10^{-3}$ & $\mathrm{~m}$ \\
Current collector thickness & $\mathrm{h}$ & $1.0 \times 10^{-3}$ & $\mathrm{~m}$ \\
Membrane thickness & $d$ & $0.1 \times 10^{-3}$ & $\mathrm{~m}$ \\
\hline
\end{tabular}

The inlet velocity was set to deliver a flowrate of 7.5 stoich. This was chosen as it is the average of the common five and 10 stoich flowrates used in previous studies of mixers and wedge geometries $[17,26]$. The electrolyte is assumed to have constant physical properties. Key parameters are shown below in Table 2. The Kozeny-Carman equation was used to define the permeability of the electrodes as a function of porosity.

Table 2. Model parameters from Knehr et al. [14].

\begin{tabular}{cccc}
\hline Parameter & Symbol & Value & Unit \\
\hline Dynamic viscosity (negative electrolyte) & $\mu_{-}$ & 0.0025 & $\mathrm{~Pa} \mathrm{~s}$ \\
Dynamic viscosity (positive electrolyte) & $\mu_{+}$ & 0.005 & $\mathrm{~Pa} \mathrm{~s}$ \\
Density (negative electrolyte) & $\rho_{-}$ & 1300 & $\mathrm{~kg} \mathrm{~m}^{-3}$ \\
Density (positive electrolyte) & $\rho_{+}$ & 1350 & $\mathrm{~kg} \mathrm{~m}^{-3}$ \\
Mean pore radius & $r_{p}$ & $50.3 \times 10^{-6}$ & $\mathrm{~m}$ \\
Kozeny-Carman constant & $k_{C K}$ & 180 & - \\
Conductivity of current collector & $\sigma_{s}^{c c}$ & 1000 & $\mathrm{~S} \mathrm{~m}^{-1}$ \\
\hline
\end{tabular}

Data published by Park et al. [31] for carbon felt electrodes at various states of compression was used for electrical conductivity and porosity parameters, as shown below in Table 3.

Table 3. Carbon felt electrode data adapted from Park et al. [31].

\begin{tabular}{ccccc}
\hline Thickness & \multicolumn{2}{c}{ Compression } & Conductivity & Porosity \\
\hline $\mathbf{m m}$ & $\mathbf{m m}$ & $\mathbf{\%}$ & $\mathbf{S} / \mathbf{m}$ & \\
\hline 4.0 & 0.0 & $0 \%$ & 5.9 & 0.95 \\
3.6 & 0.4 & $10 \%$ & 14.3 & 0.90 \\
3.2 & 0.8 & $20 \%$ & 20.0 & 0.89 \\
2.8 & 1.2 & $30 \%$ & 50.0 & 0.87 \\
\hline
\end{tabular}

Electrochemical properties used are summarised in Table 4 for reference. A Bruggeman correction was applied to diffusion coefficients and electrical conductivity parameters. 
Table 4. Electrochemical parameters from You et al. [12].

\begin{tabular}{cccc}
\hline Parameter & Symbol & Value & Unit \\
\hline $\mathrm{V}^{2+}$ diffusion coefficient & $D_{V^{2+}}$ & $2.4 \times 10^{-10}$ & $\mathrm{~m}^{2} \mathrm{~s}^{-1}$ \\
$\mathrm{~V}^{3+}$ diffusion coefficient & $D_{V^{3+}}$ & $2.4 \times 10^{-10}$ & $\mathrm{~m}^{2} \mathrm{~s}^{-1}$ \\
$\mathrm{VO}^{2+}$ diffusion coefficient & $D_{V O^{2+}}$ & $3.9 \times 10^{-10}$ & $\mathrm{~m}^{2} \mathrm{~s}^{-1}$ \\
$\mathrm{VO}_{2}^{+}$diffusion coefficient & $D_{V O_{2}^{+}}$ & $3.9 \times 10^{-10}$ & $\mathrm{~m}^{2} \mathrm{~s}^{-1}$ \\
Proton diffusion coefficient & $D_{H^{+}}$ & $9.312 \times 10^{-9}$ & $\mathrm{~m}^{2} \mathrm{~s}^{-1}$ \\
Initial vanadium concentration & $c^{0}$ & 1500 & $\mathrm{~mol} \mathrm{~m}^{-3}$ \\
Initial proton concentration (negative) & $c_{n_{H+}}^{0}$ & 4500 & $\mathrm{~mol} \mathrm{~m}^{-3}$ \\
Initial proton concentration (positive) & $c_{p_{H+}}^{0}$ & 6000 & $\mathrm{~mol} \mathrm{~m}^{-3}$ \\
Standard reaction rate constant (negative) & $k_{c}$ & $1.7 \times 10^{-7}$ & $\mathrm{~m} \mathrm{~s}^{-1}$ \\
Standard reaction rate constant (positive) & $k_{c}$ & $6.8 \times 10^{-7}$ & $\mathrm{~m} \mathrm{~s}^{-1}$ \\
Anodic transfer coefficient & $\alpha_{a}$ & 0.5 & - \\
Cathodic transfer coefficient & $\alpha_{c}$ & 0.5 & - \\
Equilibrium potential: $\mathrm{V}^{2+} / \mathrm{V}^{3+}$ & $E_{c}^{0}$ & -0.255 & $\mathrm{~V}$ \\
Equilibrium potential: $\mathrm{VO}^{2+} / \mathrm{VO}_{2}^{+}$ & $E_{a}^{0}$ & 1.004 & $\mathrm{~V}$ \\
\hline
\end{tabular}

The full-cell model used for this research showed good agreement with the published experimental data with parameters defined by You et al. [12]. This includes a small voltage correction which the researchers used to account for considerations that are not included in the simplified model, such as contact resistances. With $150 \mathrm{mV}$ added to each value, the average error over the range $10 \%$ to $90 \%$ SOC was $1 \%$, and the maximum error at $10 \%$ was $3 \%$. Experimental and simulated charge curves are shown in Figure 3 below.

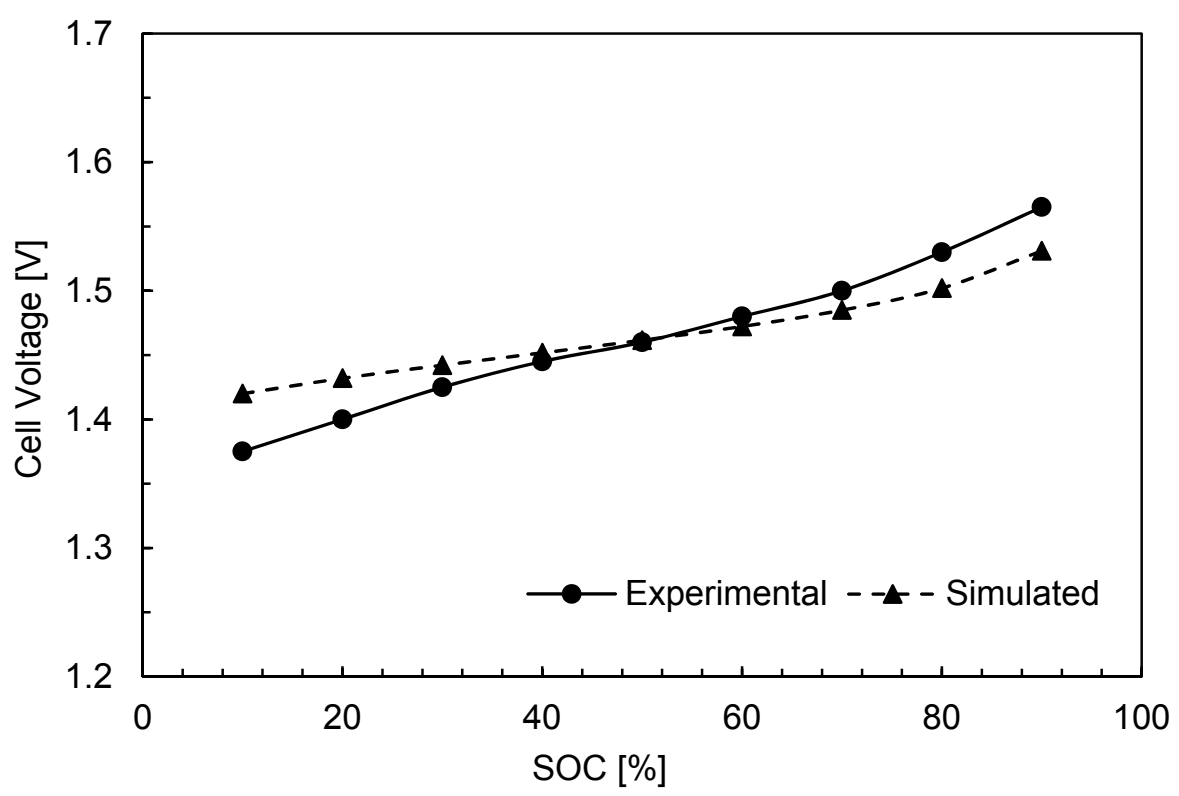

Figure 3. Experimental [12] and simulated charge curves for a $5 \mathrm{~cm}^{2}$ cell at $40 \mathrm{~mA} \mathrm{~cm}^{-2}$ from $10 \%$ to $90 \%$ SOC for model validation.

Performance parameters were obtained through post-processing in COMSOL, with derived values providing the minimum $\mathrm{V}^{3+}$ concentration over the negative electrode cross-section. The electric potential was measured at the current collector boundary at the positive half-cell, implemented with a boundary probe. This boundary was defined as an electrode current set at the applied average current density, while the negative was given an electric ground boundary condition. Differential pressure values were extracted by subtracting the inlet boundary average absolute pressure from that at the outlet 


\section{Results and Discussion}

Cell simulations showed higher minimum reactant concentration, and lower differential pressure and cell voltage for cases with wedge-shaped cells and mixers. The values for each case are given in Table 5, where the minimum $\mathrm{V}^{3+}$ concentration and differential pressure are for the negative half-cell.

Table 5. Key values for Cases 1, 2 and 3 for simulations of $200 \mathrm{~mm}$ long unit-width cells charged at $160 \mathrm{~mA} \mathrm{~cm}^{-2}$ from $90 \%$ SOC.

\begin{tabular}{lcccc}
\hline \multicolumn{1}{c}{ Geometry } & Electrode Compression & Min. $\mathbf{~ V}^{3+}$ Concentration & Differential Pressure & Cell Voltage \\
\hline 1-Uniform & & $\mathbf{m o l ~ m}^{-\mathbf{3}}$ & $\mathbf{k P a}$ & $\mathbf{V}$ \\
2-Wedge & $15 \%$ & 1 & 7.7 & 1.74 \\
3-Mixed Wedge & $0 \%$ to 30\% & 5 & 7.0 & 1.71 \\
\hline
\end{tabular}

The effect of the mixer is clearly seen in Figure 4, which shows the reactant distribution at the outlet boundary. Improved availability of reactants leads to lower concentration overpotentials and a higher minimum limiting current density. The improvement due to the varied electrode compression is less visible in the concentration distribution as the benefits are derived from optimizing local material properties.

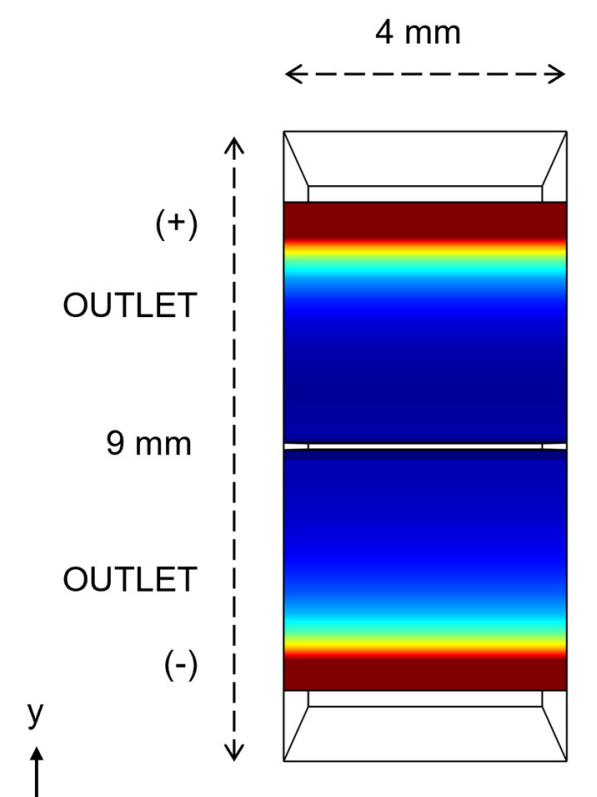

(a)

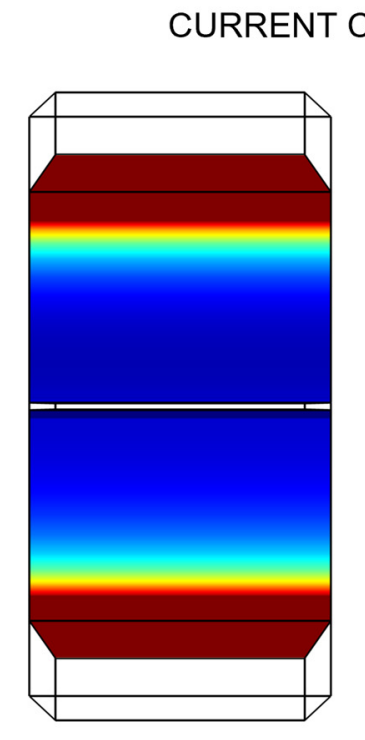

(b)

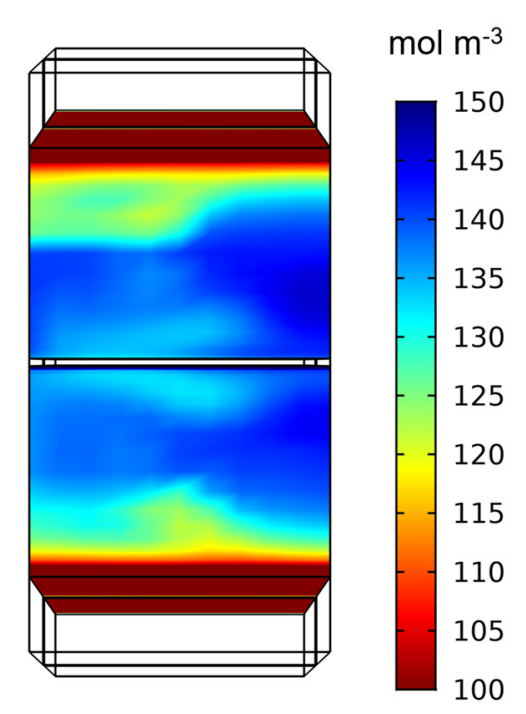

(c)

Figure 4. Concentration ( $\mathrm{mol} \mathrm{m}^{-3}$ ) of $\mathrm{V}^{4+}$ (top) and $\mathrm{V}^{3+}$ (bottom) at the outlet boundary for (a) Case 1, (b) Case 2 and (c) Case 3 showing improved electrolyte utilization during charging at high current density in a wedge-shaped cell with mixing.

The mixer mechanism is shown in Figure 5. The boundary layers are disrupted in the center of the cell by the blades, redistributing the depleted electrolyte, which carries through the cell to the outlet shown above. 


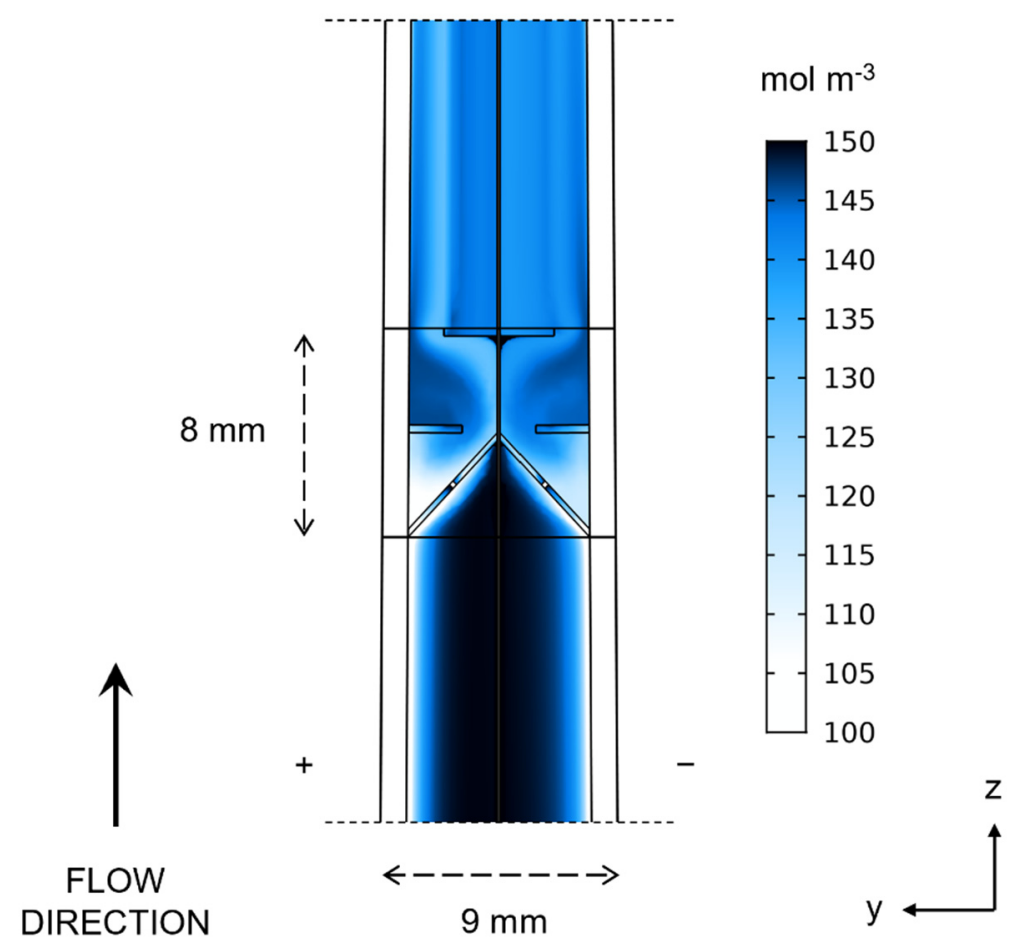

Figure 5. Concentration $\left(\mathrm{mol} \mathrm{m}^{-3}\right)$ of $\mathrm{V}^{4+}$ (left) and $\mathrm{V}^{3+}$ (right) on the unit-width cell domain boundary showing the mixing action in the positive and negative half-cells respectively over a truncated section.

The improvement in the cell voltage when compared to the reference uniform geometry was $>1 \%$ by applying reducing compression, and $>2 \%$ improvement with the addition of a mixer as well. These results were achieved in conjunction with a reduction in parasitic pressure losses across the cell, shown in Table 6, and despite the reduction in active porous electrode volume from the inserted mixers.

Table 6. Change in cell voltage and pressure drop across a $200 \mathrm{~mm}$ long unit-width cell, relative to conventional uniform reference geometry, when charged at $160 \mathrm{~mA} \mathrm{~cm}^{-2}$ from $90 \%$ SOC.

\begin{tabular}{ccc}
\hline Geometry & Pressure Drop Improvement & Cell Voltage Improvement \\
\hline Wedge without mixer & $9 \%$ & $1.6 \%$ \\
Wedge with mixer & $12 \%$ & $2.2 \%$ \\
\hline
\end{tabular}

Simulations in this work were conducted in a stationary model to reduce computational resource requirements, so while these improvements may seem small, they can translate into much more significant benefits in an operational system over time. When wedge cells without mixers were tested in laboratory cycling experiments [18] the reduction in overpotentials resulted in a $15 \%$ increase in energy efficiency, and increased energy capacity from an improved depth of charge and discharge between voltage cutoffs. With the addition of mixers, energy efficiency improvements of over $20 \%$ would be expected. If applied to batteries at the scale of a commercial stack, such as the concepts shown below, this would equate to improvements in the order of kWs and kWhs.

The capacity improvement due to the higher energy efficiency is observable in the charge-discharge curves shown in Figure 6. Digital manufacturing was used to fabricate an adjustable $25 \mathrm{~cm}^{2}$ cell with uniform and wedge flow frames for variable compression of thermally treated felt. Experimental studies were conducted to measure differential pressure and electrochemical performance for each configuration at multiple flow rates in support of numerical modelling. The single cell was cycled between 0.6 and $1.7 \mathrm{~V}$ limits with $100 \mathrm{~mL}$ of $2 \mathrm{M}$ vanadium electrolyte at $20,40,60,80$ and $100 \mathrm{~mA} \mathrm{~cm}^{-2}$ then 10 cycles at 60,80 and $120 \mathrm{~mA} \mathrm{~cm}^{-2}$. While all current densities demonstrated improved performance, the greatest 
impact on cell efficiency was seen at the highest current density. Cell resistance testing confirmed that the improvement seen below was not due to cell construction with lower contact resistance.

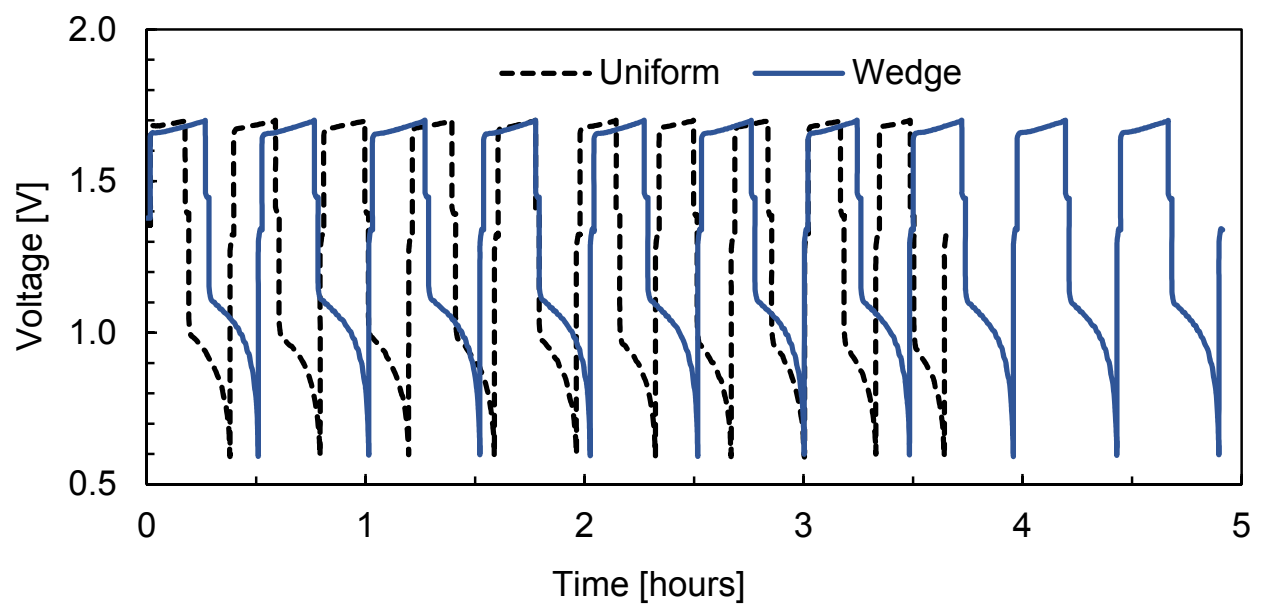

Figure 6. Charge-discharge curves demonstrating extended energy capacity in experimental studies over 10 cycles at $120 \mathrm{~mA} \mathrm{~cm}-2$ in $25 \mathrm{~cm}^{2}$ cells using conventional uniform and wedge flow-frames [18,32].

With regards to the pressure drop, the results of this study are consistent with the finding in the previous mixer study [26] - the mechanical benefit, or penalty, of the mixers depends on the electrolyte flowrate. While the stoichiometric flowrate used here was higher in relative terms, the absolute velocity is lower in this case as the cells here have a smaller active area $\left(400 \mathrm{~cm}^{2}\right.$ vs. $\left.900 \mathrm{~cm}^{2}\right)$. Further optimization of felt parameters and mixer geometries could preserve this advantage in larger cells, some of which exceed $2.5 \mathrm{~m}^{2}$, which are being developed to deliver economies of scale [33]. Simulations of one geometry variation, a helical design, recently showed improved mixing with reduced pressure drop [32].

Possible concerns for the application of mixers in flow cells include the manufacturability of the geometries, and potential damage to thin structurally weak membranes. There are commercially available mixers for pipe applications on this scale, and Figure 7 shows a grey mixer prototype 3D printed in Accura ${ }^{\circledR}$ Xtreme ${ }^{\mathrm{TM}}$ using stereolithography (SLA), sitting atop a black cube printed using fused filament fabrication (FFF) for contrast. This material is rigid, but we have previously demonstrated the ability to print at the same scale with flexible VisiJet ${ }^{\circledR}$ CE-NT using material jetting (MJP), a soft material with a Shore Hardness of 27-33A [34]. The alternative helical mixer geometry fabricated using MJP [35] is also shown below.

A toroidal vanadium redox flow battery (VRB-T) concept was first introduced at the International Flow Battery Forum [18] based on the simulation and experimental testing of wedge-shaped cells. Figure 8 shows development on this concept with internally contained pumps, providing a visualization of how wedge-shaped cells with mixers could be applied in an assembly of multiple $400 \mathrm{~cm}^{2}$ cell stacks. This novel RFB system is only possible with wedge-shaped cells, and would realize the technical advantages promised by the simulation results presented here. 


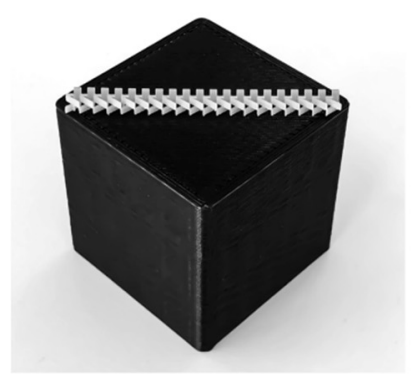

(a)

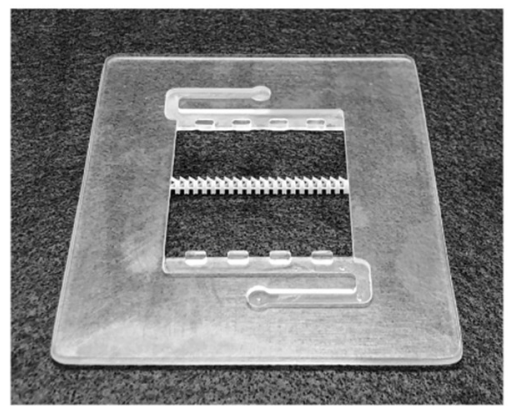

(b)

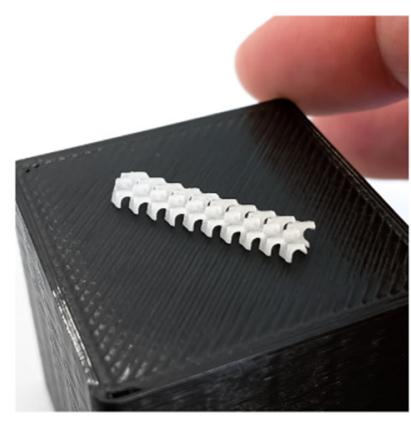

(c)

Figure 7. Prototype two-element mixers additively manufactured using (a,b) stereolithography (SLA) and (c) material jetting (MJP) [35]. The (a) blade-style and (c) helical mixers are shown on cubes made with fused filament fabrication (FFF) for contrast and on (b) felt, with an SLA printed flow frame for future experimental studies.

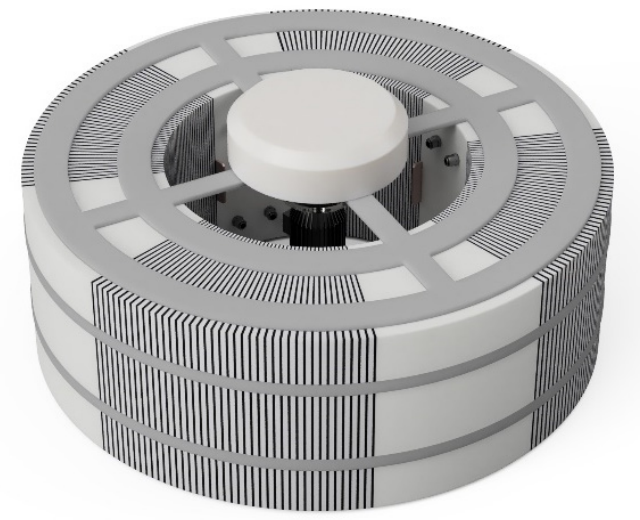

Figure 8. Rendering of $4 \times 40$ toroidal redox flow cell stack concept incorporating auxiliary plant (motor and pumps) capped and centrally mounted internally.

Public acceptance of new energy generation and storage technologies is crucial to their long-term uptake and viability within social settings, especially if they are to be seamlessly integrated into highly visible urban environments [36]. Lessons learnt from the early installations of wind turbines are instructive in this regard [37]. Without adequate engagement with the communities that the technologies were located in, significant public push back occurred. Social surveys were used to identify and resolve some of these concerns for existing and future installations. For urban environments, where deployment of these new energy storage technologies is anticipated, public acceptance will be even more important. For this reason, it is instructive to use simulations and scenario planning to ensure that adequate groundwork is carried out to facilitate the seamless integration of these new energy storage systems into existing urban landscapes and the built environment.

To promote easy recognition and association with the function of the flow cell, we have chosen to render the battery design to draw on existing consumer understanding and associations with common, and widely known household batteries. Figure 9 shows a $5 \mathrm{~kW} / 25 \mathrm{kWh}$ VRB concept with $415 \mathrm{~L}$ tanks of $1.8 \mathrm{M}$ electrolyte. This is comparable to the power of a Tesla Powerwall 2, with almost double the capacity, in a package $50 \%$ wider and higher. A system of two such batteries would be capable of providing the electricity requirements for an average Australian household. The capital cost of vanadium flow batteries is currently higher than lithium-ion systems but is expected to decrease more quickly through increased manufacturing scale [38]. 


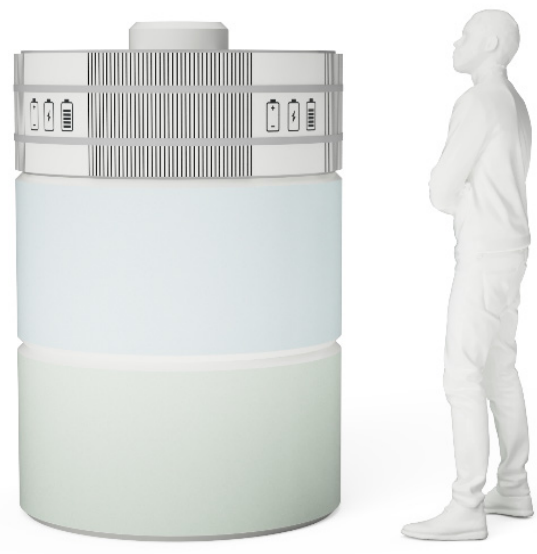

Figure 9. Rendering of $5 \mathrm{~kW} / 25 \mathrm{kWh}$ toroidal vanadium redox flow battery concept incorporating positive and negative electrolyte tanks (middle and base respectively), internal auxiliary plant and external status displays. Human model provided for scale.

Early adopters of devices such as solar panels, electric vehicles and smart appliances are motivated by technical innovation [39], while more widespread dispersion is facilitated by simplicity and observability. It is for this reason that the design resembles a D cell battery. Other advantages of this design include modularity and possible improvements to heat management with airflow through the center aided by convection. Figure 10 shows a $20 \mathrm{~kW} / 100 \mathrm{kWh}$ concept with $1660 \mathrm{~L}$ tanks of $1.8 \mathrm{M}$ electrolyte for an alternative configuration, which would have the power and capacity to meet Level 2 Fast charging specifications [40] for a full charge of two mid-size electric vehicles, such as a Hyundai Kona Electric. Electrolyte energy density improvements [41] could lead to increased capacity or more compact systems. These future developments would be readily facilitated by the modular design.

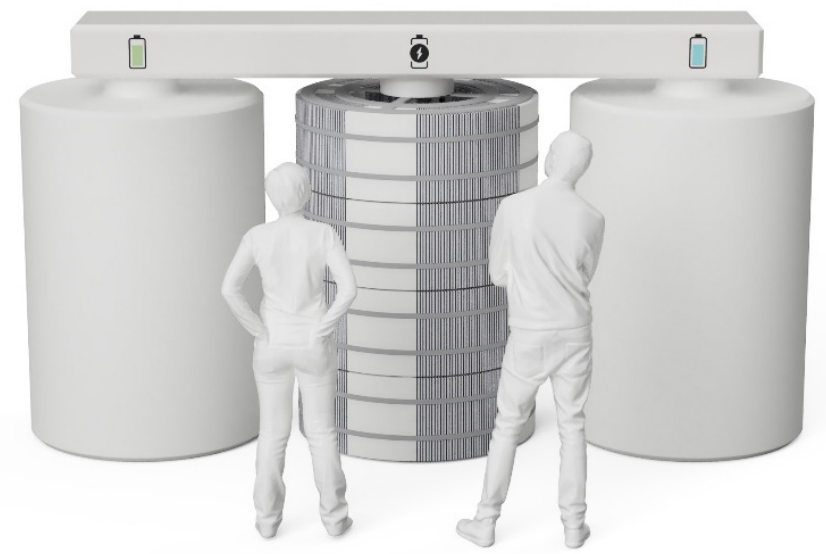

Figure 10. Rendering of $20 \mathrm{~kW} / 100 \mathrm{kWh}$ toroidal vanadium redox flow battery concept incorporating positive and negative electrolyte tanks with piping bridge and external status displays. Human models provided for scale.

\section{Conclusions}

Simulations of representative sections of $400 \mathrm{~cm}^{2}$ cells showed enhanced mechanical and electrochemical performance with the combination of wedge architecture and static mixers. A reduction in concentration overpotentials was accompanied by pressure drop reduction of over $10 \%$. The corresponding $>2 \%$ improvement in operational cell voltage would result in significantly extended cycle capacity between voltage limits and a $20 \%$ increase in energy efficiency. The promise of technical benefits from the application of wedge-shaped cells with static mixers in addressing mass 
transport issues in flow batteries, coupled with the design possibilities enabled by this innovation, make a compelling case for further development of this concept. Future research may use simulations to investigate different mixer geometries and optimize compression ratios, and complement this work with more laboratory cycling experiments to demonstrate reliable performance and aid in materials selection.

Author Contributions: Conceptualization, N.G., D.F.K., D.G. and I.K.; Formal analysis, N.G.; Funding acquisition, N.G., V.T., D.G., I.K. and C.M.; Investigation, N.G., D.F.K. and M.B.; Methodology, N.G.; Project administration, N.G.; Resources, V.T. and C.M.; Software, N.G.; Supervision, V.T. and C.M.; Validation, N.G.; Visualization, N.G.; Writing_original draft, N.G.; Writing—review \& editing, D.F.K., M.B., V.T., D.G., I.K. and C.M. All authors have read and agreed to the published version of the manuscript.

Funding: The first author acknowledges the support of an Australian Government Research Training Program (RTP) Scholarship for funding this research. Publication costs were supported by funding from the UNSW Digital Grid Futures Institute, UNSW, Sydney, under a cross disciplinary fund scheme. The views expressed here are those of the authors and are not necessarily those of the institute.

Conflicts of Interest: The authors declare no conflict of interest.

\section{Appendix A}

This appendix details the foundations of the multiphysics model used for this study, as developed by Shah, You, Knehr et al. [9,12,29]. Flow is assumed to be laminar, incompressible, and isothermal with constant physical properties. The dilute-solution approximation is used, as the bulk of the electrolyte is water, and the physical properties of the solid components are isotropic. The stationary model ignores water transport through the membrane. With the time derivative term eliminated, mass balance in the active region of the half-cell can be expressed in the following form:

$$
\nabla \cdot \vec{N}_{i}=-S_{i}
$$

where $S_{i}$ is the source term for the respective species; $\nabla \cdot \vec{i} / F$ for $V^{2+}$ and $-\nabla \cdot \vec{i} / F$ for $V^{3+} \cdot \vec{N}_{i}$ represents the concentration flux of species $i$ due to diffusion, migration and convection as described by the Nernst-Planck equations:

$$
\vec{N}_{i}=-D_{i}^{e f f} \nabla c_{i}-\frac{z_{i} c_{i} D_{i}^{e f f}}{R T} F \nabla^{2} \phi_{l}+\vec{v} c_{i}
$$

where $\vec{v}$ is the electrolyte velocity, $c_{i}$ and $z_{i}$ are the concentration and the valence of species $i$, respectively. $D_{i}^{e f f}$ is the effective diffusion coefficient of species $i$, derived by the Bruggemann correction as shown below:

$$
D_{i}^{e f f}=\varepsilon^{3 / 2} D_{i}
$$

where $D_{i}$ is the free-space value and $\varepsilon$ is the electrode porosity.

The stationary incompressible flow in the volume surrounding the mixers is characterized by the Navier-Stokes equation:

$$
\begin{gathered}
\rho(\vec{v} \cdot \nabla) \vec{v}=-p+\mu\left[\nabla \vec{v}+(\nabla \vec{v})^{T}\right] \\
\nabla \cdot \vec{v}=0
\end{gathered}
$$

Darcy's law with the Kozeny-Carman equation is added to give the velocity $\vec{v}$ in the porous region:

$$
\vec{v}=\frac{d_{f}^{2}}{K \mu} \cdot \frac{\varepsilon^{3}}{(1-\varepsilon)^{2}} \nabla p
$$


where $d_{f}$ is a mean fibre diameter, $p$ is the liquid pressure, $\mu$ is the dynamic viscosity of the liquid, and $K$ is the Kozeny-Carman constant. With the dilute-solution approximation and the incompressibility assumption, the following pressure relationship can be obtained:

$$
-\frac{d_{f}^{2}}{k \mu} \cdot \frac{\varepsilon^{3}}{(1-\varepsilon)^{2}} \nabla^{2} p=0
$$

The electrolyte is governed by the electroneutrality condition and charge conservation can be expressed as the balance of charge entering the electrolyte, $\vec{i}_{e}$, and charge leaving the solid porous electrode, $\vec{i}_{s}$ :

$$
\nabla \cdot \vec{i}_{e}+\nabla \cdot \vec{i}_{s}=0
$$

The total current transferred is equal to the volumetric electrochemical reaction rate multiplied by Faraday's constant, $F$, and so the current density for the flow of charged species $i$ is:

$$
\vec{i}_{i}=z_{i} F \vec{N}_{i}
$$

The total electrolyte current density is then:

$$
\vec{i}=\sum_{i} \vec{i}_{i}=-\kappa^{e f f} \nabla \phi_{l}-F \sum_{i} z_{i} D_{i}^{e f f} \nabla c_{i}
$$

where $\kappa^{e f f}$ is the effective conductivity, given by:

$$
\kappa^{e f f}=\frac{F^{2}}{R T} \sum_{i} z_{i}^{2} D_{i}^{e f f} c_{i}
$$

where $R$ is the gas constant and $T$ is the temperature.

Conservation of charge with Ohm's law gives the following relationship for electronic potential, $\psi$, in the electrode:

$$
-\sigma_{s}^{e f f} \nabla^{2} \psi=-\nabla \cdot \vec{i}
$$

where a Bruggemann correction is applied again to give the effective electronic conductivity, $\sigma_{S}^{e f f}$, from the electronic conductivity of the porous electrode, $\sigma_{s}$ :

$$
\sigma_{s}^{e f f}=(1-\varepsilon)^{3 / 2} \sigma_{s}
$$

The Butler-Volmer law has been shown to produce sufficient accuracy in describing the reversible redox reactions on the surface of the porous electrode. The transfer current densities can thus be expressed as:

$$
\begin{aligned}
& \nabla \cdot \vec{i}_{c}=A i_{c}^{0}\left[\frac{c_{V^{3+}}^{s}}{c_{V^{3+}}} \exp \left(\frac{\left(1-\alpha_{c}\right) F \eta_{c}}{R T}\right)-\frac{c_{V^{2+}}^{s}}{c_{V^{2+}}} \exp \left(-\frac{\alpha_{c} F \eta_{c}}{R T}\right)\right] \\
& \nabla \cdot \vec{i}_{a}=A i_{a}^{0}\left[\frac{c_{V^{5+}}^{c}}{c_{V^{5+}}} \exp \left(\frac{\left(1-\alpha_{a}\right) F \eta_{a}}{R T}\right)-\frac{c_{V^{4+}}^{s}}{c_{V^{4+}}} \exp \left(-\frac{\alpha_{a} F \eta_{a}}{R T}\right)\right]
\end{aligned}
$$

where $\alpha_{c}$ is the cathodic transfer coefficient which is assumed as 0.5 . The $c_{i}^{s}$ values are the species concentrations at the solid-liquid interface. $A$ is the specific active surface area, while $\eta_{c}$ is the overpotential in the negative electrode. The exchange current density, $i_{0}$, can be written as:

$$
i_{c}^{0}=F k_{c}\left(c_{V^{2+}}\right)^{1-\alpha_{c}}\left(c_{V^{3+}}\right)^{\alpha_{c}}
$$




$$
i_{a}^{0}=F k_{a}\left(c_{V^{4+}}\right)^{1-\alpha_{a}}\left(c_{V^{5+}}\right)^{\alpha_{a}}
$$

where $k$ is the standard rate constant for the reaction. The overpotential is defined as:

$$
\begin{aligned}
& \eta_{c}=\phi_{s}-\phi_{l}-E_{c}^{e q} \\
& \eta_{a}=\phi_{s}-\phi_{l}-E_{a}^{e q}
\end{aligned}
$$

where $\phi_{s}$ is the electric potential of the solid phase and $\phi_{l}$ is the potential of the liquid electrolyte. $E^{e q}$ is the open circuit potential, given by the following expression where $E^{0}$ denotes the equilibrium potential at standard conditions:

$$
\begin{aligned}
& E_{c}^{e q}=E_{c}^{0}+\frac{R T}{F} \ln \left(\frac{c_{V^{3+}}}{c_{V^{2+}}}\right) \\
& E_{a}^{e q}=E_{a}^{0}+\frac{R T}{F} \ln \left(\frac{c_{V^{5+}}}{c_{V^{4+}}}\right)
\end{aligned}
$$

Following the format used by Ma et al. [13], the surface concentrations for the negative electrode can be determined from the following expressions, obtained by simultaneously solving rewritten Butler-Volmer terms.

$$
\begin{aligned}
& c_{V^{2+}}^{s}=\frac{P c_{V^{3+}}+(1+P) c_{V^{2+}}}{1+M+P} \\
& c_{V^{3+}}^{s}=\frac{M c_{V^{3+}}+(1+P) c_{V^{2+}}}{1+M+P}
\end{aligned}
$$

where:

$$
\begin{gathered}
M=\frac{k_{c}}{k_{m}}\left(c_{V^{2+}}\right)^{\alpha_{c}-1}\left(c_{V^{3+}}\right)^{1-\alpha_{c}} \exp \left(\frac{\alpha F \eta_{c}}{R T}\right) \\
P=\frac{k_{c}}{k_{m}}\left(c_{V^{2+}}\right)^{\alpha_{c}}\left(c_{V^{3+}}\right)^{-\alpha_{c}} \exp \left(-\frac{\alpha F \eta_{c}}{R T}\right)
\end{gathered}
$$

and $k_{m}$ is a mass transfer coefficient, which can be approximated by:

$$
k_{m}=1.6 \times 10^{-4} \vec{v}^{0.4}
$$

The positive half-cell is similarly defined. A fixed space charge, $\rho_{f i x}$, is added for the ion-exchange membrane domain in terms of charge concentrations and is initialized using an auxiliary sweep:

$$
\rho_{f i x}+F \sum_{i=1}^{n} z_{i} c_{i}=0
$$

The membrane-porous electrode boundaries use Donnan potentials [29] for the relationship to the concentration of species on both sides:

$$
\phi_{l . m}=\phi_{l, e}-\frac{R T}{z_{i} F} \ln \left(\frac{c_{i . m}}{c_{i, e}}\right)
$$

where $c_{i . m}$ is the concentration in the membrane and $c_{i, e}$ the concentration in the free electrolyte, and is the corresponding charge.

For galvanostatic operation an 'Electric Ground', $\phi_{s}=0$, condition was applied to the negative current collector boundary while an 'Electrode Current' condition was applied to the positive collector boundary, which can be expressed in the form:

$$
-\sigma_{s} \nabla \phi_{s} \cdot \vec{n}=I
$$


where $I$ is defined as the applied current density and $\vec{n}$ is the normal outward unit vector.

Inlet concentrations were defined based on SOC and $c_{0}$ the initial vanadium concentration:

$$
\begin{gathered}
c_{V^{2+}}^{i n}=c^{0} \cdot S O C \\
c_{V^{3+}}^{i n}=c^{0} \cdot(1-S O C) \\
c_{V^{4+}}^{i n}=c^{0} \cdot(1-S O C) \\
c_{V^{5+}}^{i n}=c^{0} \cdot S O C
\end{gathered}
$$

For fluid flow, the inlet was defined with a normal velocity and the outlet with zero relative pressure. Boundaries on the $y-z$ plane were set as symmetry planes. All other boundaries were defined as no slip walls with no flux.

\section{References}

1. BloombergNEF. Energy Storage Investments Boom As Battery Costs Halve in the Next Decade, Bloomberg. 2019. Available online: https://about.bnef.com/blog/energy-storage-investments-boom-battery-costs-halvenext-decade/ (accessed on 17 April 2019).

2. Ziegler, M.S.; Mueller, J.M.; Pereira, G.D.; Song, J.; Ferrara, M.; Chiang, Y.M.; Trancik, J.E. Storage Requirements and Costs of Shaping Renewable Energy Toward Grid Decarbonization. Joule 2019, 3, 2134-2153. [CrossRef]

3. Skyllas-Kazacos, M.; Menictas, C.; Lim, T. Redox flow batteries for medium to large scale energy storage. In Electricity Transmission, Distribution and Storage Systems; Melhem, Z., Ed.; Woodhead Publishing: Sawston, Cambridge, UK, 2013; pp. 398-441.

4. Tang, A.; Bao, J.; Skyllas-Kazacos, M. Studies on pressure losses and flow rate optimization in vanadium redox flow battery. J. Power Sources 2014, 248, 154-162. [CrossRef]

5. Kim, K.J.; Park, M.-S.S.; Kim, Y.-J.J.; Kim, J.H.; Dou, S.X.; Skyllas-Kazacos, M. A technology review of electrodes and reaction mechanisms in vanadium redox flow batteries. J. Mater. Chem. A 2015, 3, 16913-16933. [CrossRef]

6. Arenas, L.F; de León, C.P.; Walsh, F.C. Redox flow batteries for energy storage: Their promise, achievements and challenges. Curr. Opin. Electrochem. 2019, 16, 117-126. [CrossRef]

7. Aaron, D.S.; Liu, Q.; Tang, Z.; Grim, G.M.; Papandrew, A.B.; Turhan, A.; Zawodzinski, T.A.; Mench, M.M. Dramatic performance gains in vanadium redox flow batteries through modified cell architecture. J. Power Sources 2012, 206, 450-453. [CrossRef]

8. Ke, X.; Prahl, J.M.; Alexander, J.I.D.; Wainright, J.S.; Zawodzinski, T.A.; Savinell, R.F. Rechargeable redox flow batteries: Flow fields, stacks and design considerations. Chem. Soc. Rev. 2018. [CrossRef]

9. Shah, A.A.; Watt-Smith, M.J.; Walsh, F.C. A dynamic performance model for redox-flow batteries involving soluble species. Electrochim. Acta 2008, 53, 8087-8100. [CrossRef]

10. Shah, A.A.; Al-Fetlawi, H.; Walsh, F.C. Dynamic modelling of hydrogen evolution effects in the all-vanadium redox flow battery. Electrochim. Acta 2010, 55, 1125-1139. [CrossRef]

11. Shah, A.A.; Tangirala, R.; Singh, R.; Wills, R.G.A.; Walsh, F.C. A Dynamic Unit Cell Model for the All-Vanadium Flow Battery. J. Electrochem. Soc. 2011, 158, A671. [CrossRef]

12. You, D.; Zhang, H.; Chen, J. A simple model for the vanadium redox battery. Electrochim. Acta 2009, 54, 6827-6836. [CrossRef]

13. Ma, X.; Zhang, H.; Xing, F. A three-dimensional model for negative half cell of the vanadium redox flow battery. Electrochim. Acta 2011, 58, 238-246. [CrossRef]

14. Knehr, K.W.; Agar, E.; Dennison, C.R.; Kalidindi, A.R.; Kumbur, E.C. A Transient Vanadium Flow Battery Model Incorporating Vanadium Crossover and Water Transport through the Membrane. J. Electrochem. Soc. 2012, 159, A1446-A1459. [CrossRef]

15. Yue, M.; Zheng, Q.; Zhang, H.; Li, X.; Ma, X. Flow field design and optimization of high power density vanadium flow batteries: A novel trapezoid flow battery. AICHE J. 2017, 13-18. [CrossRef] 
16. Gurieff, N.; Cheung, C.Y.Y.; Timchenko, V.; Menictas, C. Performance enhancing stack geometry concepts for redox flow battery systems with flow through electrodes. J. Energy Storage 2019, 22, 219-227. [CrossRef]

17. Gurieff, N.; Timchenko, V.; Menictas, C. Variable Porous Electrode Compression for Redox Flow Battery Systems. Batteries 2018, 4, 53. [CrossRef]

18. Gurieff, N.; Menictas, C.; Timchenko, V.; Skyllas-Kazacos, M.; Noack, J. Performance enhancing stack geometry concepts. In Proceedings of the International Flow Battery Forum, Lyon, France, 9-11 July 2019. [CrossRef]

19. Brown, L.D.; Neville, T.P.; Jervis, R.; Mason, T.J.; Shearing, P.R.; Brett, D.J.L. The effect of felt compression on the performance and pressure drop of all-vanadium redox flow batteries. J. Energy Storage 2016, 8, 91-98. [CrossRef]

20. Hsieh, C.L.; Tsai, P.H.; Hsu, N.Y.; Chen, Y.S. Effect of compression ratio of graphite felts on the performance of an all-vanadium redox flow battery. Energies 2019, 12, 313. [CrossRef]

21. Yoon, S.J.; Kim, S.; Kim, D.K. Optimization of local porosity in the electrode as an advanced channel for all-vanadium redox flow battery. Energy 2019, 172, 26-35. [CrossRef]

22. Kim, Y.; Choi, Y.Y.; Yun, N.; Yang, M.; Jeon, Y.; Kim, K.J.; Choi, J.I. Activity gradient carbon felt electrodes for vanadium redox flow batteries. J. Power Sources 2018, 408, 128-135. [CrossRef]

23. Chen, W.; Kang, J.; Shu, Q.; Zhang, Y. Analysis of storage capacity and energy conversion on the performance of gradient and double-layered porous electrode in all-vanadium redox flow batteries. Energy 2019, 180, 341-355. [CrossRef]

24. Lu, M.-Y.; Yang, W.-W.; Bai, X.-S.; Deng, Y.-M.; He, Y.-L. Performance improvement of a vanadium redox flow battery with asymmetric electrode designs. Electrochim. Acta 2019, 319, 210-226. [CrossRef]

25. Zheng, Q.; Xing, F.; Li, X.; Liu, T.; Lai, Q.; Ning, G.; Zhang, H. Dramatic performance gains of a novel circular vanadium flow battery. J. Power Sources 2015, 277, 104-109. [CrossRef]

26. Gurieff, N.; Keogh, D.F.; Timchenko, V.; Menictas, C. Enhanced Reactant Distribution in Redox Flow Cells. Molecules 2019, 24, 3877. [CrossRef] [PubMed]

27. Percin, K.; Rommerskirchen, A.; Sengpiel, R.; Gendel, Y.; Wessling, M. 3D-printed conductive static mixers enable all-vanadium redox flow battery using slurry electrodes. J. Power Sources 2018, 379, 228-233. [CrossRef]

28. Bayatsarmadi, B.; Horne, M.; Rodopoulos, T.; Gunasegaram, D. Intensifying Diffusion-Limited Reactions by Using Static Mixer Electrodes in a Novel Electrochemical Flow Cell. J. Electrochem. Soc. 2020, 167, 063502. [CrossRef]

29. Knehr, K.W.; Kumbur, E.C. Open circuit voltage of vanadium redox flow batteries: Discrepancy between models and experiments. Electrochem. Commun. 2011, 13, 342-345. [CrossRef]

30. Zheng, Q.; Zhang, H.; Xing, F.; Ma, X.; Li, X.; Ning, G. A three-dimensional model for thermal analysis in a vanadium flow battery. Appl. Energy 2014, 113, 1675-1685. [CrossRef]

31. Park, S.K.; Shim, J.; Yang, J.H.; Jin, C.S.; Lee, B.S.; Lee, Y.S.; Shin, K.H.; Jeon, J.D. The influence of compressed carbon felt electrodes on the performance of a vanadium redox flow battery. Electrochim. Acta 2014, 116, 447-452. [CrossRef]

32. Gurieff, N.; Keogh, D.F.; Menictas, C.; Timchenko, V. Static Mixers for Enhanced Reactant Distribution in Redox Flow Cells. In Proceedings of the The International Coalition for Energy Storage and Innovation, Sydney, Australia, 1-4 May 2020. [CrossRef]

33. Minke, C.; Kunz, U.; Turek, T. Techno-economic assessment of novel vanadium redox flow batteries with large-area cells. J. Power Sources 2017, 361, 105-114. [CrossRef]

34. 3D Systems, VisiJet CE-NT (MJP) —Technical Specifications. 2019. Available online: https://au.3dsystems. $\mathrm{com} /$ materials/visijet-ce-nt-elastomeric-natural/tech-specs (accessed on 17 October 2019).

35. Gurieff, N.; Baldry, M.; Keogh, D.F. Rapid prototyping the next generation of energy devices. In Proceedings of the UNSW Engineering Postgraduate Research Symposium, Sydney, Australia, 9 December 2019. [CrossRef]

36. Boudet, H.S. Public perceptions of and responses to new energy technologies. Nat. Energy 2019, 4, 446-455. [CrossRef]

37. Rand, J.; Hoen, B. Thirty years of North American wind energy acceptance research: What have we learned? Energy Res. Soc. Sci. 2017, 29, 135-148. [CrossRef]

38. Lazard. Lazard's Levelized Cost of Storage Analysis-Version 4.0; Lazard: New York City, NY, USA, 2018.

39. Schelly, C. Residential solar electricity adoption: What motivates, and what matters? A case study of early adopters. Energy Res. Soc. Sci. 2014, 2, 183-191. [CrossRef] 
40. Raveendran, V.; Divya, R.; Chandran, P.C.S.; Nair, M.G. Smart level 2 DC electric vehicle charging station with improved grid stability and battery backup. In Proceedings of the 2017 International Conference on Technological Advancements in Power and Energy (TAP Energy), Kollam, India, 21-23 December 2017; IEEE: Piscataway, NJ, USA, 2018; pp. 1-6. [CrossRef]

41. Roe, S.; Menictas, C.; Skyllas-Kazacos, M. A High Energy Density Vanadium Redox Flow Battery with 3 M Vanadium Electrolyte. J. Electrochem. Soc. 2016, 163, A5023-A5028. [CrossRef]

(C) 2020 by the authors. Licensee MDPI, Basel, Switzerland. This article is an open access article distributed under the terms and conditions of the Creative Commons Attribution (CC BY) license (http://creativecommons.org/licenses/by/4.0/). 